eCommons@AKU

THE AGA KHAN UNIVERSITY

Department of Medicine

Section of Diabetes, Endocrinology and

Metabolism

September 2016

\title{
Burden of Diabetes Mellitus and Role of Telemedicine in its Management: Narrative Review
}

Gulshan Bano

Aga Khan University, gulshan.bano@aku.edu

Savera Aziz Ali

Aga Khan University, savera.azizali@aku.edu

Minaz Mawani

Aga Khan University, minaz.mawani@aku.edu

Sumera Aziz Ali

Aga Khan University, sumera.ali@aku.edu

Follow this and additional works at: http://ecommons.aku.edu/

pakistan_fhs_mc_med_diabet_endocrinol_metab

Part of the Endocrinology, Diabetes, and Metabolism Commons

\section{Recommended Citation}

Bano, G., Ali, S. A., Mawani, M., Ali, S. A. (2016). Burden of Diabetes Mellitus and Role of Telemedicine in its Management: Narrative Review. Annals of Clinical and Laboratory Research., 4(3), 113-120.

Available at: http://ecommons.aku.edu/pakistan_fhs_mc_med_diabet_endocrinol_metab/23 


\title{
Burden of Diabetes Mellitus and Role of Telemedicine in its Management: Narrative Review
}

\author{
Gulshan Bano ${ }^{1}$, Savera Aziz Ali ${ }^{2}$, Minaz Mawani ${ }^{3}$ and Sumera Aziz Ali ${ }^{1}$ \\ ${ }^{1}$ Department of Community Health Sciences, Aga Khan University, Karachi, Pakistan \\ ${ }^{2}$ School of Nursing and Midwifery, Aga Khan University, Karachi, Pakistan \\ ${ }^{3}$ Department of Medicine, Aga Khan University, Karachi, Pakistan
}

Corresponding author: Sumera Aziz Ali, Department of Community Health Sciences, Aga Khan University, Karachi, Pakistan, Tel: +92134864837; E-mail: Sumera.ali@aku.edu

Received: 14 July 2016; Accepted: 16 August 2016; Published: 20 August 2016

Citation: Bano G, Ali SA, Mawani M, et al. Burden of Diabetes Mellitus and Role of Telemedicine in its Management: Narrative Review. Ann Clin Lab Res. 2016, 4: 3.

\section{Abstract}

Objective: The purpose of this review is to summarize the findings regarding the prevalence and risk factors of Diabetes Mellitus in developed and developing world and to review the management options for Diabetes Mellitus especially the role of telemedicine.

Methodology: Extensive literature review was carried by retrieving articles from various databases like Pub med, Google scholar, Science direct, Scopus and Archives of Medicine. Relevant articles were retrieved from different databases by using text words and phrases like 'Diabetes Mellitus', 'Management', 'risk factors', 'prevalence of Diabetes', 'telemedicine', 'e- health'. Types of studies were descriptive studies, systematic reviews and various reports.

Findings: Various supporting systems have been made to upgrade the management of type 2 Diabetes Mellitus including mobile phones and internet. Mobile phones and internet are mechanical support tools for the patients with type $2 \mathrm{DM}$ to improve their health by facilitating good communication between the patients and their respective health care providers.

Conclusion: There are multiple ways of managing Diabetes Mellitus ranging from oral medicines to insulin. These can be done either through the visits to the patients or the patients can be reminded to take the medicines through telemedicine. Telemedicine can play an important role in managing the patients with chronic diseases including Diabetes Mellitus.

Keywords: Diabetes mellitus; Management; Telemedicine

\section{Introduction}

Diabetes Mellitus is one of the chronic diseases which can affect almost all age groups worldwide. Approximately 150 million people have diabetes mellitus worldwide, and this number may well double by the year 2025. Prevalence of this disease seems to be increasing and among all the diabetic cases in the world more than $90 \%$ are type 2 DM. Type 2 DM cannot be cured permanently however various methods are available worldwide to manage this disease.

\section{Background}

Diabetes Mellitus (DM) is a metabolic disorder, diagnosed by the high level of glucose in the blood. It is possible in two conditions. Firstly, when the pancreas does not produce sufficient amount of insulin compared to the requirements of the body and secondly when the body is unable to properly utilize the insulin. Uncontrolled DM ends up with high blood sugar and with the passage of time it causes serious harm to many parts of the body, especially the nervous and cardiovascular system [1].

There are two major types of DM, type I and type II. Type I DM (formerly known as insulin- dependent DM or child onset DM) is a life-long condition, affecting children, young people and adults worldwide. Type II DM is a non-insulin dependent DM, closely linked with sedentary lifestyle and obesity [2]. The purpose of this review is to summarize the findings regarding the prevalence and risk factors of Diabetes Mellitus in developed and developing world and to review the management options for Diabetes Mellitus especially the role of telemedicine.

\section{Methodology}

An extensive review was carried out by retrieving articles from various databases like Pub med, Google scholar, Science direct, Scopus Archives of Medicine and World Bank and WHO databases. Relevant articles were retrieved from different databases by using following text words and phrases: 'Diabetes 
Mellitus', 'Management', 'risk factors', 'prevalence of Diabetes', 'telemedicine', 'e-health'. Types of studies included were descriptive studies, observational studies, correlational studies and comparative studies. In addition to this; different reports were also being studied including World Health Organization and World Bank reports. A literature search was completed within the six months from January 2012 to July 2012 except for few articles and reports which were also retrieved later on. The inclusion criteria for the studies was that the studies have been written in the English language, from 2000 to 2013, reporting data on the burden of Diabetes Mellitus, risk factors and management of Diabetes Mellitus.

The review was extensively done by the primary and secondary author of this study and only those articles were included in the literature review for which both of the authors showed agreement.

\section{Prevalence of diabetes mellitus globally}

Diabetes Mellitus is one of the chronic diseases which can affect almost all age groups worldwide. Approximately 150 million people have diabetes mellitus worldwide, and this number may well double by the year 2025 [3]. By 2025, most people with diabetes in developed countries will be aged 65 years or more, in developing countries most will be in the 45-64 year age bracket and affected in their most productive years [3]. Diabetes Mellitus is one of the chronic diseases which can affect almost all age groups worldwide. Prevalence of this disease seems to be increasing and among all the diabetic cases in the world more than 90\% are type $2 \mathrm{DM}[4,5]$. Literature shows that every year approximately 7 million individuals develop this chronic disease. In 2000, 171 million people were suffering from DM all over the world [6], this number has reached to 285 million in 2010. It is anticipated that this number will rise up to 439 million cases in the next few years, hence the number of individuals in developing and developed countries will increase by $69 \%$ and $20 \%$, respectively [7].

Over $80 \%$ of DM deaths took place in developing countries. World Health Organization [WHO] estimates that, DM deaths might double between 2005 and 2030 [4]. Total number of deaths attributed to DM in 2010 showed an overall $5.5 \%$ increase as compared to the estimates for the year 2007. This rise in number of deaths are due to a $29 \%$ increase in North America and Caribbean Region, a 12\% in the South East Asia Region and $11 \%$ increase in the Western Pacific Region [8].

\section{Prevalence of diabetes mellitus in developing world}

It has been estimated that, during 2010 and 2030 there would be $69 \%$ and $20 \%$ increase in the number of cases of DM in developing and developed countries as described above, because in developing countries, early diagnosis of DM is very unsatisfactory and half of the people with DM are diagnosed in late stages. Besides this, adequate treatment of the disease is also a big issue which leads to rise in number of deaths in developing countries [8]. Compared to other regions of the world, percentage of people with DM is very high in Asian countries. It was estimated in 2010 that the regional prevalence was $7.0 \%$, and it was expected to increase up to $8.4 \%$ by 2030 [9].

While doing a comparison with the rest of the world, India and China were reported to have the highest prevalence of DM in 2009. In India it was estimated that around 50.8 million people were suffering with DM and has relatively more number of people with DM compared to china and Pakistan [9]. A study was conducted in India, reported that the prevalence in female individuals was $16.7 \%$ and in males it was 9.7\% [10]. While in China approximately 43.2 million individuals were suffering from DM [8].

In 2003 the prevalence of DM in Pakistan was 6.2\%, while it was anticipated at that time that it would increase to $11.6 \%$ in 2025 [11]. According to International Diabetic Federation, overall prevalence in Pakistan was 7.6\% in 2010 [12]. Since it is increasing very rapidly, we can assume that the prevalence would be much higher than the estimated prevalence in 2010.

A study conducted in 2007 in Pakistan found that glucose intolerance including DM was $22.04 \%$ in urban areas and $17.15 \%$ in rural areas [13]. It shows that the people who are living in the urban area are more prone to DM as compared to those in a rural area. But overall, in rural and urban areas, both males and females are suffering from DM, as shown in Table 1.

Table 1 Prevalence and incidence of type 2 Diabetes Mellitus in Pakistan.

\begin{tabular}{|c|c|c|c|c|c|}
\hline \multirow{2}{*}{$\begin{array}{l}\text { Author and Year of } \\
\text { Study }\end{array}$} & \multirow[t]{2}{*}{ Place of Study } & \multirow{2}{*}{$\begin{array}{l}\text { Study Size, Sample } \\
\text { Size }\end{array}$} & \multicolumn{3}{|c|}{ Prevalence (\%) of Type 2 DM } \\
\hline & & & Male & Female & Overall \\
\hline Zafar et al. [15] & Rawalpindi & Community, 1091 & 15.41 & 12.31 & 13.14 \\
\hline Shera et al. [15] & $\begin{array}{lcr}\text { Multan } & \text { and } & \text { rural } \\
\text { Mankot } & \text { areas } & \text { of } \\
\text { Punjab } & & \end{array}$ & Community, 1852 & 12.41 & 9.83 & \\
\hline Shera et al. [15] & $\begin{array}{l}\text { All four provinces of } \\
\text { Pakistan }\end{array}$ & Community, 5433 & 12.14 & 9.83 & \\
\hline Basit et al. [16] & Baluchistan & Community, 2032 & 10.1 & 4.3 & 6.3 \\
\hline
\end{tabular}




\begin{tabular}{|l|l|l|l|l|l|}
\hline Shera et al. [17] & $\begin{array}{l}\text { Baluchistan [Quetta, } \\
\text { killimengal] }\end{array}$ & Community, 1404 & 11.1 & 10.6 & 10.8 \\
\hline Shera et al. [17] & KPK [Pakistan] & Community, 1035 & 9.2 & 11.6 & 11.1 \\
\hline Shera [19] & Shikarpur & Community, 967 & 9 & 6.3 & \\
\hline
\end{tabular}

\section{Risk factors of type-2 diabetes mellitus}

Risk factors of type 2 DM are mainly divided into two categories i.e., modifiable and non-modifiable. Modifiable risk factors included obesity, sedentary lifestyle, high blood pressure and dietary intake [20]. By controlling these risk factors development of type $2 \mathrm{DM}$ can be prevented on a large scale. Non-modifiable risk factors are age, genetics i.e., family history, which cannot be modified. Among all these risk factors, most important risk factors are family history, obesity, lack of exercise and dietary intake, reported by different studies conducted in different settings including Australia, Japan and USA [21-23].

The chances of development of type $2 \mathrm{DM}$ is much greater in the first degree relatives with DM found by a cross-sectional study recently conducted [in 2012] in Turkey on 125 participants [24]. An another cohort study [mean follow-up of 23.5 years initiated in 1974] conducted in Finland on 18,831 persons (16061 Swedish and 2770 Finnish) found in 2008 that individuals with a family history of DM and obesity are more prone to develop type $2 \mathrm{DM}$ as compared to the people who do not have family members with such history [25].

Obesity is one of the most important independent risk factors for the development of type 2 DM. A retrospective cohort study conducted in Japan on 969 males and 585 female reported that hazard ratio for the development of type 2 DM among individuals with BMI 25 to 27.4 was 3.12 while for those whose BMI was 27.5 or greater was 3.80 , and concluded that obesity can independently cause type 2 DM [26]. Obesity itself may be caused by over eating, inactive lifestyle or genetics. Fast food [high fat and high sugar food] has been considered as one of the causes of obesity. A study conducted in the USA reported that changing dietary pattern i.e., reducing high fat intake and increasing fruits and vegetables can reduce the weight in obese people [27]. Healthy and nutritious diet should be preferred over fast food to prevent obesity, which in turn will reduce the chances of development of type 2 DM [28]. Central obesity is more dangerous and those who have central obesity are at higher risk of developing diabetes, which is being caused by fast food and sedentary lifestyle [29].

Exercise is considered the most efficient behavioral therapy for type 2 DM prevention and management [30]. Exercise aids in blood glucose absorption and maintains its level in the body according to body's requirement [31,32]. Various clinical trials demonstrated that the lifestyle interventions reduce the risk of developing type 2 diabetes [33]. A follow-up study conducted in UK on 3012 men in 2012 observed that even light physical activity can prevent the development of diabetes in older age groups [34].
Diet plays a major role both in the prevention [35] and management of type 2 DM [36]. Over eating of high calorie foods like fast food is very dangerous, it can lead to central obesity as well as various chronic diseases like heart disease and type 2 DM [37]. Dietary interventions showed a reduction in the development of diabetes found by a review study conducted [in 2012] in Harokopio University [Dept. of Nutrition and dietetics] Greece, on the role of diet in prevention and management of type 2 DM [38]. Another study was conducted in Massachusetts, the USA on 312 participants found that lifestyle intervention especially diet plays a major role in the risk reduction of type 2 DM by reducing weight and caloric percentage from total and saturated fat [39].

Similar to other countries the risk of developing type 2 DM in Pakistani population is very high. Risk factors of diabetes are increasing in Pakistan like other countries in spite of having awareness. [40]. Major risk factors of type 2 DM in Pakistani population are obesity, family history, hypertension, and increased age found by a cross-sectional study conducted in Rawalpindi in July 2008 on 1091 subjects [14].

\section{Findings of Literature Review}

\section{Management of diabetes}

Type 2 DM cannot be cured permanently, however, various methods are available worldwide to manage this disease. Around the world majority of the diabetic patients are being treated with physical activity, diet, and medicines (oral medications and Insulin).

\section{Management by using Insulin and oral medicines}

Insulin is prescribed for patients with uncontrolled type 2 DM because it is difficult to manage with oral medication and behavioral modification in such patients. Oral medication can only control the disease in moderate situations. But there are several side-effects reported with the oral hypoglycemic medicines and Insulin. Troglitazone is an oral drug which can cause liver toxicity [41] and Acarbose is responsible for flatulence and diarrhea [42]. Various studies provide evidence that treating patients with Insulin increases the weight of the patients $[43,44]$, which can be an adverse effect on the prognosis of the disease. But it has been proven that the combined treatment of type 2 DM i.e., physical activity and dietary counseling with medication is more beneficial [45]. Medications are always prescribed with dietary guidelines and counseling because patients will not be able to control the disease alone with medicines without compliance to dietary guidelines especially recommended for DM. 


\section{Management by physical activity}

Evidence also shows that physical activity plays a major role in both prevention and prognosis of the majority of chronic diseases including type 2 DM [46]. Physical activity includes brisk walking, exercise, jogging and any type of activity which keeps an individual physically active and healthy. It helps in the regulation of glucose in the body. Various studies reported that routine exercise can improve the $\mathrm{HbA} 1 \mathrm{c}$ in diabetic patients $[47,48]$, which is an indication of control of blood glucose in the past three months. For diabetic patients, daily physical activity is recommended for homeostasis of glucose level. A systematic review study was conducted in 2001 on the effectiveness of self-management training in type 2 diabetes, found that out of total 84 articles 72 articles gave positive results on the effectiveness of behavioral interventions including physical activity and diet in reducing the blood glucose level in the diabetic patients [49].

\section{Management by diet}

Especially in the case of type $2 \mathrm{DM}$, blood glucose and body weight of diabetic patients can be controlled by taking care of diet [50], however, more counseling and motivation is a need for its effectiveness [51]. Diet can deteriorate as well as help in the prognosis of the disease, but it depends on how much a diabetic patient understands about the dietary management. Weight loss by controlling dietary intake in diabetic patients can improve DM by lowering the blood glucose in the body [52]. Lower glucose can reduce the complications of type 2 DM, which can be maintained with the help of dietary guidelines and proper monitoring [53]. Among diabetic patients dietary compliance is a big issue therefore dietary guidelines should be very clear and well organized, in order to make the patients understand and adhere to them [54]. Dietary compliance on regular basis can improve the diabetic conditions of diabetic patients. Without dietary compliance a patient cannot control his or her blood glucose with only medication and [55] and physical activity.

\section{Role of Tele-Health in Disease Management}

\section{Telemedicine}

The definition of telemedicine is the use of telecommunications to support health care. Telemedicine includes timely transmission and remote interpretation of patient data for follow up and preventative interventions [56]. By the use of various forms of information technology like the internet, mobile phone calls, text messages [short message service] and television programs the provision of treatment can be made more effective. The key purpose of telemedicine is to strengthen the communication between patients and the health care provider which may lead to the improvement of patient's health and minimizes the cost of the treatment. Mediums which are being used to distribute the health care are mobile phones, digital diaries, laptop computers and clinical decision support systems [CDSS] [57]. To make the information or the intervention more effective, counseling material can be distributed through phone calls, text messages [short message services], e-mails and online video conversations over the internet [58].

\section{Telemedicine in developed countries}

Telemedicine improves the quality of health care delivery in the developed countries. Developed countries such as USA, UK, Sweden, Australia, New Zealand, France, Switzerland etc., have adopted telemedicine in the health care settings to minimize the cost of the health care $[59,60]$. They developed advance networks of electronic health and telemedicine in their rural areas so that the people could easily access health care, which minimize the cost of travel to large cities. Telemedicine is being used more efficiently in USA [61], UK $[62,63]$, Australia and New Zeeland [64,65].

It's more challenging to deliver health care all over the world in 21st century. Majority of the electronic health and telemedicine services provided in the developed countries are based on the diagnosis and clinical management of the chronic diseases, especially in United Kingdom, Scandinavia, Australia and North America [66-68]. Measuring and monitoring devices for heart rate, blood pressure and level of glucose in the body are also used to remotely manage the patients at distant places at homes [69], especially in those areas where people can't easily access health care services. However certain issues are being faced by the developed counties in provision of health care through telemedicine and its implementation. Major issues include breach in patient privacy and confidentiality, competition in various priorities of health system and perceived lack of demand [70].

\section{Telemedicine in developing countries}

Work is going on feasibility and cost effectiveness of telemedicine in most of the developing countries like China, India, Pakistan, Bangladesh, Cambodia and Africa etc. [71,72]. Health care provision is very difficult and is more expensive for individuals living in rural settings, hence telemedicine can improve the health status of individuals living in rural areas of the developing countries [73]. Various strategies are being studied in many parts of the developing world, like prototype systems to transfer the results of the bioassays digitally to the expert health care provider [74] and store-and-forward e-mail consultative support for mobile non-physician health care workers to deliver the health care [75]. However, high cost, poor infrastructure and absence of technical expertise are considered to be major hurdles in implementing telemedicine in developing countries [70].

In Pakistan, telemedicine was introduced in 1998, since then it developed rapidly [76]. The majority of the tertiary care hospitals are situated in big cities like Islamabad, Karachi, Lahore, Peshawar, Quetta and Multan etc. Individuals living in the rural areas were facing problems in receiving good health care. In the recent years because of advancement in the telemedicine techniques like store and forward and real time 
medicine $[77,78]$ made delivery of health care easy in these rural settings to some extent. Telemedicine is used in Pakistan in various fields of health care provision like dermatology [79], to diagnose the TB cases [80] and antenatal care provision [81]. A hospital based cross-sectional study was conducted in Rawalpindi in 2007 on current status of e-health awareness among health care professionals, reported that majority are having access to e- health but some are practicing [82]. However, very little work has been done in the field of telemedicine for prevention and treatment of type $2 \mathrm{DM}$.

\section{M-health}

Mobile health is a wireless health technology is an area of electronic health which comes under the domain of telemedicine. This is an evolving method to improve the communication between the health care provider and the patient [83]. Throughout the world there has been rising interest in health sector to utilize mobile phone in health care setting. Communications with mobile phones are increasing rapidly with the time both in developed and developing countries. In 2002 number of mobile phones used in worldwide exceeded the landline and its use in developing world increasing at a higher rate, which can be helpful in exchanging information about health in these settings [84].

\section{Use of mobile phone in health care provision}

Enormous use of media and other electronic devices in the field of health care has shown success in motivating patients to improve their health behaviors. Examples of such technologies include television, computers, Internet $[85,86]$ and mobile phones $[87,88]$. A study conducted at St. Gabriel's Hospital in Malawi, where community health workers were supplied with mobile phone and were fully trained about its use in the far flung rural areas for different purposes including patient compliance reporting, physician queries, and appointment reminders. It was found that total 2,048 hours of working time was saved, fuel saving was $\$ 2,750$ and the capacity of tuberculosis treatment program was doubled, up to 200 patients [89].

Another study conducted in USA reported that use of mobile phone is an inexpensive technique to promote health care provision and its utilization in health care system in treatment of various diseases like diabetes, asthma, high blood pressure and chlamydia trachomatis infection [90]. A study was conducted on mobile phones with camera to see its use for clinical microscopy and applicability for global health. The author reported a positive result after designing an instrument contains camera-enable mobile and microscope eye piece, which can help in the early diagnosis of different infectious diseases in those settings where technical equipment's are not available [91]

Mobile phone was also used to see the adherence of the patients with antiretroviral treatment. A randomized control trial conducted in Kenya in 2010 in three different clinics on 538 participants, reported that those who were being reminded through mobile text messages showed a greater adherence to the treatment [92]. Similarly another trial conducted in Korea on 51 participants to see the effectiveness of cellular phone and SMS in glucose control and behavioral modifications in diabetic participant found a significant decrease in the HbA1c [93].

\section{Use of mobile phone in the management of diabetes}

Research carried out on the use of mobile phones in the tertiary health care settings in developed countries, especially in diabetic individuals, proved that it can improve the blood glucose levels by motivating the patients to adhere to the treatment [medications] [94].

Mobile phones and internet are mechanical support tools for the patients with type 2 DM to improve their health by facilitating good communication between the patients and expert endocrinologist. Various supporting systems have been made to upgrade the management of type 2 DM. A randomized trial on mobile tele-monitoring in diabetic patients was conducted in UK, reported that it is helpful in the maintenance of blood pressure and glucose [95]. It helps in collecting data to improve the intervention action on blood glucose levels, $\mathrm{HbA1c}$, behavioral change, such as dietary modification, exercise, medication dosages and number of emergency visits [58].

A review study was conducted in 2009 [includes published studies between January 1990 and March 2008] on behavioral change interventions delivered by mobile telephone shortmessage service, showing 33 such studies, out of which 14 met their inclusion criteria. 4 out of 14 studies reviewed targeted preventive health behaviors, Ex: smoking cessation (other studies also reported that use of mobile phone for smoking cessation is very effective [96]), and 10 focused on clinical care (Ex: type 2 DM self-management). According to this review, positive behavior change outcomes were observed in 13 out of the 14 studies [97].

Various studies have been done on mobile text message to manage incurable diseases like diabetes, with the help of behavior modification $[98,99]$. Studies have proved that by motivating patients with reminders through text messages can improve compliance to dietary counseling and improved conditions of the patients. A randomized control trial conducted in Netherland on type 2 diabetic patients (207 subjects) to see the improvements in the adherence to treatment by using Real Time Medication Monitoring and mobile text message, found it as an effective method [100]. Recently a study was done in USA to assess the feasibility and acceptance of mobile text message by the diabetic patients and reported positive response was found and it was recommended that its use will prove to be beneficial [101]. One another stud on importance of SMS especially in poor resource setting conducted in India and it was reported that this technique can be used as an innovative approach to fight chronic diseases like type 2 DM [102]. 


\section{Conclusion}

There could be multiple ways of managing Diabetes Mellitus ranging from oral medicines to insulin. Management of Diabetes can be done either through the visits to the patients or the patients can be reminded to manage the chronic diseases including Diabetes Mellitus. Telemedicine has played an important role in the management of multiple chronic diseases. Thus, telemedicine can be used to remind the patients to improve their compliance to the medicines of Diabetes Mellitus.

\section{References}

1. WHO (2012) What is diabetes?.

2. Beran D (2007) Report on the rapid assessment protocol for insulin access:idf. Diabetes Voice 49: 2.

3. WHO (2015) Diabetes mellitus: World Health organization.

4. WHO (2011) A Report on Diabetes.

5. LaMonte MJ, Blair SN, Church TS (2005) Physical activity and diabetes prevention. J Appl Physiol 99: 1205-1213.

6. WHO (2006) Diagnosis of diabetes mellitus and intermediate hyperglycemia: report of a WHO/IDF consultation. Geneva: World Health Organization.

7. Shaw JE, Sicree RA, Zimmet PZ (2009) Global estimates of the prevalence of diabetes for 2010 and 2030. Diabetes research and clinical practice 87: 4-14.

8. Diabetes fact (2011) World Diabetes Foundation.

9. Diabetes A (2010) Regional Overview (South-East Asia).

10. Scavini M, Stidley CA, Shah VO, Narva AS, Tentori F, et al. (2003) Prevalence of diabetes is higher among female than male Zuni Indians. Diabetes Care 26: 55.

11. Sierra GN (2009) The global pandemic of diabetes. Afr J Diabetic Med 17: 4-8.

12. Diabetes A (2009) Proportion of people with diabetes (20-79 years), 2010 (comparative prevalence).

13. Shera AS, Jawad F, Maqsood A (2007) Prevalence of diabetes in Pakistan. Diabetes Research and Clinical Practice 76: 219-222.

14. Zafar J, Bhatti F, Akhtar N, Rasheed U, Bashir R, et al. (2011) Prevalence and risk factors for diabetes mellitus in a selected urban population of a city in Punjab. J Pak Med Assoc 61: 40-47.

15. Shera AS, Basit A, Fawwad A, Hakeem R, Ahmedani MY, et al. (2010) Pakistan National Diabetes Survey: Prevalence of glucose intolerance and associated factors in the Punjab Province of Pakistan. Primary care diabetes 4: 79-83.

16. Basit A, Hydrie MZ, Ahmed K, Hakeem R (2002) Prevalence of diabetes, impaired fasting glucose and associated risk factors in a rural area of Baluchistan province according to new ADA criteria. J Pak Med Assoc 52: 357-360.

17. Shera AS, Rafique G, Khawaja IA, Baqai S, King H (1999) Pakistan National Diabetes Survey: prevalence of glucose intolerance and associated factors in Baluchistan province. Diabetes research and clinical practice 44: 49-58.

18. Shera AS, Rafique G, Khwaja IA, Baqai S, Khan IA, et al. (1999) Pakistan National Diabetes Survey prevalence of glucose intolerance and associated factors in North West at Frontier Province (NWFP) of Pakistan. JPMA The Journal of the Pakistan Medical Assoc 49: 206.

19. Shera AS, Rafique G, Khwaja IA, Ara J, Baqai S, King H (1995) Pakistan national diabetes survey: prevalence of glucose intolerance and associated factors in Shikarpur, Sindh Province. Diabetic medicine 12: 1116-1121.

20. Zafar J, Bhatti F, Akhtar N, Rasheed U, Bashir R, et al. (2011) Prevalence and risk factors for diabetes mellitus in a selected urban population of a city in Punjab. JPMA The Journal of the Pakistan Medical Association 61: 40.

21. Azzopardi P, Brown AD, Zimmet P, Fahy RE, Dent GA, et al. (2012) Type 2 diabetes in young Indigenous Australians in rural and remote areas: diagnosis, screening, management and prevention. Med J Aust 197: 32-36.

22. Fujimoto WY, Boyko EJ, Hayashi T, Kahn SE, Leonetti DL, et al. (2012) Risk Factors for Type 2 Diabetes: Lessons Learned from Japanese Americans in Seattle. J Diabetes Investig 3: 212-224.

23. Liu JC, Guo ZR, Hu XS, Zhou ZY, Wu M, et al. (2012) (Relationship of lifestyle and obesity to the risk of type 2 diabetes: a prospective study in Jiangsu province). Zhonghua Yu Fang Yi Xue Za Zhi 46: 311-315.

24. Karaman A, Bayram F, Gundogan K, Ozsan M, Karaman H, et al. (2012) Prevalence of diabetes mellitus and glucose metabolism disorders in the first degree relatives of type 2 diabetic patients. Bratisl Lek Listy 113: 361-367.

25. Lyssenko $\mathrm{V}$, Jonsson $\mathrm{A}$, Almgren $\mathrm{P}$, Pulizzi $\mathrm{N}$, Isomaa $\mathrm{B}$, et al. (2008) Clinical risk factors, DNA variants, and the development of type 2 diabetes. New England Journal of Medicine 359: 2220-2232.

26. Sanada $H$, Yokokawa $H$, Yoneda $M$, Yatabe J, Sasaki Yatabe $M$, et al. (2012) High Body Mass Index is an Important Risk Factor for the Development of Type 2 Diabetes. Intern Med 51: 1821-1826.

27. Epstein LH, Gordy CC, Raynor HA, Beddome M, Kilanowski CK, et al. (2001) Increasing fruit and vegetable intake and decreasing fat and sugar intake in families at risk for childhood obesity. Obesity 9: 171-178.

28. Salmeron J, Hu FB, Manson JAE, Stampfer MJ, Colditz GA, et al. (2001) Dietary fat intake and risk of type 2 diabetes in women. The American journal of clinical nutrition 73: 1019-1026.

29. McTernan CL, McTernan PG, Harte AL, Levick PL, Barnett AH, et al. (2002) Resistin, central obesity, and type 2 diabetes. The Lancet 359: 46-47.

30. Zinman B, Ruderman N, Campaigne BN, Devlin JT, Schneider SH (2004) Physical activity/exercise and diabetes. Diabetes Care 27: S58.

31. Suh SH, Paik IY, Jacobs K (2007) Regulation of blood glucose homeostasis during prolonged exercise. Mol Cells 23: 272-279.

32. Mendham AE, Coutts AJ, Duffield R (2012) The acute effects of aerobic exercise and modified rugby on inflammation and glucose homeostasis within Indigenous Australians. Eur J Appl Physiol.

33. Sigal RJ, Kenny GP, Wasserman DH, Castaneda-Sceppa C, White RD (2006) Physical activity/exercise and type 2 diabetes. Diabetes Care 29: 1433-438.

34. Jefferis BJ, Whincup PH, Lennon L, Wannamethee SG (2012) Longitudinal Associations Between Changes in Physical Activity 
and Onset of Type 2 Diabetes in Older British Men: The influence of adiposity. Diabetes Care.

35. Laatikainen T, Philpot B, Hankonen N, Sippola R, Dunbar JA, et al. (2012) Predicting changes in lifestyle and clinical outcomes in preventing diabetes: the Greater Green Triangle Diabetes Prevention Project. Prev Med 54: 157-161.

36. Moise MM, Benjamin LM, Doris TM, Dalida KN, Augustin NO (2012) Role of Mediterranean diet, tropical vegetables rich in antioxidants, and sunlight exposure in blindness, cataract and glaucoma among African type 2 diabetics. Int J Ophthalmol 5: 231-237.

37. Astrup A, Dyerberg J, Selleck M, Stender S (2008) Nutrition transition and its relationship to the development of obesity and related chronic diseases. obesity reviews 9: 48-52.

38. Lazarou C, Panagiotakos D, Matalas AL (2012) The role of diet in prevention and management of type 2 diabetes: implications for public health. Crit Rev Food Sci Nutr 52: 382-389.

39. Ockene IS, Tellez TL, Rosal MC, Reed GW, Mordes J, et al. (2012) Outcomes of a Latino community-based intervention for the prevention of diabetes: the Lawrence Latino Diabetes Prevention Project. Am J Public Health 102: 336-342.

40. Hjellset VT, Bjarge B, Eriksen HR, Stmark AT (2011) Risk factors for type 2 diabetes among female Pakistani immigrants: The InvaDiab-DEPLAN study on Pakistani immigrant women living in Oslo, Norway. Journal of Immigrant and Minority Health 13: 101-110.

41. Knowler WC, Barrett-Connor E, Fowler SE, Hamman RF, Lachin JM, et al. (2002) Reduction in the incidence of type 2 diabetes with lifestyle intervention or metformin. The New England Journal of Medicine 346: 393.

42. Chiasson JL, Josse RG, Gomis R, Hanefeld $M$, Karasik $A$, et al. (2002) Acarbose for prevention of type 2 diabetes mellitus: the STOP-NIDDM randomised trial. The Lancet 359: 2072-2077.

43. Carver C (2006) Insulin treatment and the problem of weight gain in type 2 diabetes. The Diabetes Educator 32: 910.

44. RussellJD, Khan R (2007) Insulin-associated weight gain in diabetes--causes, effects and coping strategies. Obesity and Metabolism 9: 799-812.

45. Chan JL, Abrahamson MJ (2003) Pharmacological management of type 2 diabetes mellitus: rationale for rational use of insulin. Mayo Clin Proc 78: 459-467.

46. Warburton DE, Nicol CW, Bredin SSD (2006) Health benefits of physical activity: the evidence. Canadian Medical Association Journal 174: 801.

47. Salvatoni A, Cardani R, Biasoli R, Salmaso M, De Paoli A, et al. (2005) Physical activity and diabetes. Acta Biomed 76: 85-88.

48. Castaneda C, Layne JE, Munoz-Orians L, Gordon PL, Walsmith J, et al. (2002) A randomized controlled trial of resistance exercise training to improve glycemic control in older adults with type 2 diabetes. Diabetes Care 25: 2335-2341.

49. Norris SL, Engelgau MM, Narayan KMV (2001) Effectiveness of self-management training in type 2 diabetes. Diabetes Care 24 561-587.

50. Heilbronn LK, Noakes M, Clifton PM (1999) Effect of energy restriction, weight loss, and diet composition on plasma lipids and glucose in patients with type 2 diabetes. Diabetes Care 22: 889.
51. Costa Jde A, Balga RS, Alfenas Rde C, Cotta RM (2011) Health promotion and diabetes: discussing the adherence and motivation of diabetics that participate in health programs. Cien Saude Colet 16:2001-2009.

52. Klein S, Sheard NF, Pi-Sunyer X, Daly A, Wylie-Rosett J, et al. (2004) Weight management through lifestyle modification for the prevention and management of type 2 diabetes: rationale and strategies. Diabetes Care 27:2067.

53. Nayeri ND, Aghajani M (2010) Patients' privacy and satisfaction in the emergency department: a descriptive analytical study. Nursing ethics 17: 167-177.

54. Kim HS, Oh JA (2003) Adherence to diabetes control recommendations: impact of nurse telephone calls. Journal of Advanced Nursing 44: 256-261.

55. Williamson AR, Hunt AE, Pope JF, Tolman NM (2000) Recommendations of dietitians for overcoming barriers to dietary adherence in individuals with diabetes. The Diabetes Educator 26: 272-279.

56. Klonoff DC (2009) Using telemedicine to improve outcomes in diabetes an emerging technology. J Diabetes Sci Technol 3: 624-628.

57. Kareem S, Bajwa IS (2012) Virtual Telemedicine and Virtual Telehealth: A Natural Language Based Implementation to Address Time Constraint Problem

58. Klonoff DC (2009) Using telemedicine to improve outcomes in diabetes an emerging technology. Journal of diabetes science and technology 3: 624 .

59. Moser PL, Hauffe H, Lorenz IH, Hager M, Tiefenthaler W, et al. (2004) Publication output in telemedicine during the period January 1964 to July 2003. J Telemed Telecare 10: 72-77.

60. Demiris G, Tao D (2005) An analysis of the specialized literature in the field of telemedicine. Journal of telemedicine and telecare 11: 316-319.

61. Choi YB, Krause JS, Seo H, Capitan KE, Chung K (2006) Telemedicine in the USA: standardization through information management and technical applications. Communications Magazine, IEEE 44: 41-48.

62. Debnath D (2004) Activity analysis of telemedicine in the UK. Postgraduate medical journal 80: 335-338.

63. Wootton R, Loane M, Mair F, Allen A, Doolittle G, et al. (1998) A joint US-UK study of home telenursing. Journal of telemedicine and telecare 4: 83-85.

64. Mitchell J (2000) Increasing the cost-effectiveness of telemedicine by embracing e-health. Journal of telemedicine and telecare 6: 16-19.

65. Wilson LS, Gill RW, Sharp IF, Joseph J, Heitmann SA, et al. (2000) Building the hospital without walls-a CSIRO home telecare initiative. Telemedicine Journal 6: 275-281.

66. Craig J, Patterson V (2005) Introduction to the practice of telemedicine. Journal of telemedicine and telecare 11: 3-9.

67. Eedy DJ, Wootton R (2001) Teledermatology: a review. British Journal of Dermatology 144: 696-707.

68. Smith AC, Bensink M, Armfield N, Stillman J, Caffery L (2005) Telemedicine and rural health care applications. Journal of postgraduate medicine 51: 286 .

69. Heinzelmann PJ, Lugn NE, Kvedar JC (2005) Telemedicine in the future. Journal of telemedicine and telecare 11: 384-390. 
70. WHO (2009) Telemedicine: opportunities and developments in Member States: report on the second global survey on eHealth 2009. Geneva: WHO Library Cataloguing-in-Publication Data Dostopno prek.

71. Adler AT (2000) A cost-effective portable telemedicine kit for use in Developing countries: Massachusetts Institute of Technology.

72. Johnston K, Kennedy C, Murdoch I, Taylor P, Cook C (2004) The cost-effectiveness of technology transfer using telemedicine. Health policy and planning 19: 302-309.

73. Blaya JA, Fraser HSF, Holt B (2010) E-health technologies show promise in developing countries. Health Affairs 29: 244-251.

74. Martinez AW, Phillips ST, Carrilho E, Thomas lii SW, Sindi H (2008) Simple telemedicine for developing regions: camera phones and paper-based microfluidic devices for real-time, offsite diagnosis. Analytical chemistry 80: 3699-3707.

75. Brandling-Bennett HA, Kedar I, Pallin DJ, Jacques G, Gumley GJ (2005) Delivering health care in rural Cambodia via store-andforward telemedicine: a pilot study. Telemedicine Journal \& eHealth 11: 56-62.

76. Ullah N, Khan P, Sultana N, Kwak KS (2009) A Telemedicine Network Model for Health Applications in Pakistan: Current Status and Future Prospects. International Journal of Digital Content Technology and its Applications 3: 149-155.

77. Kareem S, Bajwa IS (2012) Virtual Telemedicine and Virtual Telehealth.

78. Karim S, Bajwa IS (2011) Clinical Decision Support System based Virtual Telemedicine. Intelligent Human-Machine Systems and Cybernetics (IHMSC) International Conference.

79. Rashid E, Ishtiaq O, Gilani S, Zafar A (2003) Comparison of store and forward method of teledermatology with face-to-face consultation. J Ayub Med Coll Abbottabad 15: 34-36.

80. Marcelo A, Fatmi Z, Firaza PN, Shaikh S, Dandan AJ, et al. (2011) An online method for diagnosis of difficult TB cases for developing countries. Studies in health technology and informatics 164: 168.

81. Khalid MZ, Akbar A, Tanwani AK, Tariq A, Farooq M (2008) Using telemedicine as an enabler for antenatal care in Pakistan. 2nd International Conference E-Medisys: E-Medical Systems, Sfax.

82. Shoaib SF, Mirza S, Murad F, Malik AZ (2009) Current status of ehealth awareness among healthcare professionals in teaching hospitals of Rawalpindi: a survey. Telemed J E Health 15: 347-352.

83. Istepanian RSH, Lacal JC (2003) Emerging mobile communication technologies for health: some imperative notes on $\mathrm{m}$-health. In Engineering in Medicine and Biology Society 2: 1414-1416.

84. Donner J (2008) Research approaches to mobile use in the developing world: A review of the literature. The information society $24: 140-159$.

85. Tate DF, Jackvony EH, Wing RR (2003) Effects of internet behavioral counseling on weight loss in adults at risk for type 2 diabetes. JAMA: the journal of the American Medical Association 289: 1833

86. Kim SI, Kim HS (2008) Effectiveness of mobile and internet intervention in patients with obese type 2 diabetes. International journal of medical informatics 77: 399-404.
87. Rotheram-Borus MJ, Tomlinson M, Gwegwe M, Comulada WS, Kaufman N (2012) Diabetes Buddies Peer Support Through a Mobile Phone Buddy System. The Diabetes Educator 38: 357-365.

88. Ferrer-Roca O, Cardenas A, Diaz-Cardama A, Pulido P (2004) Mobile phone text messaging in the management of diabetes. Journal of telemedicine and telecare 10: 282.

89. Mahmud N, Rodriguez J, Nesbit J (2010) A text message-based intervention to bridge the healthcare communication gap in the rural developing world. Technology and Health Care 18: 137-144.

90. Patrick K, Griswold WG, Raab F, Intille SS (2008) Health and the mobile phone. American journal of preventive medicine 35: 177.

91. Breslauer DN, Maamari RN, Switz NA, Lam WA, Fletcher DA (2009) Mobile phone based clinical microscopy for global health applications. PLoS One 4: e6320.

92. Lester RT, Ritvo P, Mills EJ, Kariri A, Karanja S, et al. (2010) Effects of a mobile phone short message service on antiretroviral treatment adherence in Kenya (WelTel Kenya1): a randomised trial. The Lancet 376: 1838-1845.

93. Yoon KH, Kim HS (2008) A short message service by cellular phone in type 2 diabetic patients for 12 months. Diabetes research and clinical practice 79: 256-261.

94. Franklin VL, Waller A, Pagliari C, Greene SA (2006) A randomized controlled trial of Sweet Talk, a text messaging system to support young people with diabetes. Diabetic medicine 23: 1332-1338.

95. Istepanian RSH, Sungoor A, Earle KA (2009) Technical and compliance considerations for mobile health self-monitoring of glucose and blood pressure for patients with diabetes. IEEE 5130 - 5133.

96. Stead LF, Perera R, Lancaster T (2006) The Cochrane Database Systematic R. Telephone counselling for smoking cessation. The Cochrane Library.

97. Fjeldsoe BS, Marshall AL, Miller YD (2009) Behavior Change Interventions Delivered by Mobile Telephone Short-Message Service. American Journal of Preventive Medicine 36: 165-173.

98. Siriwardena LS, Wickramasinghe WA, Perera KL, Marasinghe RB, Katulanda $P$, et al. (2012) A review of telemedicine interventions in diabetes care. Journal of telemedicine and telecare. 18: 164-168.

99. Krishna S, Boren SA, Balas EA (2009) Healthcare via cell phones: a systematic review. Telemedicine and e-Health 15: 231-240.

100. Vervloet M, van Dijk L, Santen-Reestman J, van Vlijmen B, Bouvy ML (2011) Improving medication adherence in diabetes type 2 patients through Real Time Medication Monitoring: a Randomised Controlled Trial to evaluate the effect of monitoring patients' medication use combined with short message service (SMS) reminders. BMC health services research 11: 5 .

101. Mulvaney SA, Anders S, Smith AK, Pittel EJ, Johnson KB (2012) A pilot test of a tailored mobile and web-based diabetes messaging system for adolescents. Journal of telemedicine and telecare 18: 115-118.

102. Ajay VS, Prabhakaran D (2011) The scope of cell phones in diabetes management in developing country health care settings. Journal of diabetes science and technology 5: 778. 